\title{
Is our dietary advice effective?
}

\author{
BY A. E. DE LOOY*, P. L. AUTY AND C. A. COATES \\ Faculty of Health \& Social Care, Leeds Polytechnic, Calverley Street, Leeds LS1 $3 H$ E
}

The concept of 'being effective' or having an effect is very attractive to us all. It is the way we may come to justify our very presence as a profession (Simko \& Conklin, 1989; MacDonald, 1990). If, as highly paid professionals, our advice is largely ineffectual then our employment is hard to justify (Ley, 1982). The effectiveness of any advice must be the extent to which it is acted upon by the recipient. The ability to monitor change is, therefore, an important component of judging effectiveness.

Measuring compliance is one critical aspect to the study of effectiveness. In the medical model compliance is often tested by an objective criterion such as a clinical measure. In dietetics and nutrition it may well be a change in food habits. But these criteria in themselves may offer little help to the dietitian who finds therapy 'ineffective' and wishes to change practice. First, advice is not by definition compulsory; it is open to acceptance or not. Second, whether the advice is followed may be based on factors beyond the control of the individual, such as their income (MacDonald \& Forsythe, 1986). So the dietitian may well be effective in educating the patient or group, but unless appropriate evaluation measures are used to test this aspect specifically the more traditional methods of monitoring may not reveal the success. General estimates of compliance with advice lie in the region of 15-50\% (Bloom, 1967; Davidson et al. 1987).

In an audit of an obesity clinic Pacy et al. (1987) make this statement: 'Patients are not referred to the clinic . . . if their obesity is of a type which responds readily to conventional dietary advice, so easy therapeutic success is not to be expected'. Would success in this rather difficult clinic situation equate to that in another? The issue of comparability becomes important if one trial is judged more effective than another. Also the variability of response of individuals means that goals may be set unrealistically high. Again Pacy et al. (1987) make this observation 'the striking feature is the great variation within a group of patients in response to any treatment.' Dietitians when monitoring their ability to successfully meet their targets would do well to build an allowance into the target outcomes. Thus, McManners \& Barina (1984) set a target of $75 \%$ for achievement of outcomes and Drexler \& Caliendo (1980) quote $85 \%$.

The model suggested by Simko \& Conklin (1989) for assessing effectiveness is attractive by virtue of its simplicity. The emphasis on comparing two methods before claiming effectiveness of either is important. But the model also assumes that risk factors can be identified and desirable health outcomes quantified. A reduction in total fat intake in the English population has not occurred but the deaths from cardiovascular disease have declined over the past 10 years (Department of Health, 1991). This illustrates that dietary change may not be the only change element which modifies the risk factors. Often large-scale nutrition education programmes have proved ineffective in changing dietary habits (Murray et al. 1984; Nichols et al. 1988), but successful in raising knowledge and awareness. Dietitians need to choose outcomes which are amenable and appropriate to the dietetic investigation (MacDonald, 1990).

* Present address: Department of Dietetics and Nutrition, Queen Margaret College, Edinburgh EH12 8TS. 


\section{FACTORS AFFECTING COMPLIANCE}

Knowledge about the diet, educational attainment and motivation are factors which can affect compliance. Three studies (Cole-Hamilton et al. 1986; Warwick \& Williams, 1987; Bradley \& Theobald, 1988) looked at compliance with dietary advice but each took a different group of subjects in whom knowledge and motivation could have been said to be widely different. The groups were, respectively, dietitians, health-conscious volunteers and the third group men and women from the 'high street'. All three studies involved the group changing their diet to match nutritional goals, all participants achieved a change in dietary intake over 1 week and the level of success commensurate with recommendations was notable. Each group, however, found it much easier to substitute one item in the diet for another or reduce consumption of certain foods. These were often the items in the diet which contained or contributed a significant amount of fat such as margarine and milk. Interestingly each group found it difficult to increase the consumption of carbohydrate foods and so maintain their energy levels. Thomas (1979) notes that an area of misunderstanding in the general public is over starch. Often people fail to eat more of 'starch' foods for fear of becoming obese (Warwick \& Williams, 1987). This must indicate the success of earlier nutrition campaigns such as one by Yudkin (1958) in the 1950 s and early 1960s. In the short term dietary change may be relatively easy, but over the longer term availability of foods, especially snack foods (Bradley \& Theobald, 1988) could make adherence difficult. Fehily et al. (1991) comment that individuals in the DART trial found it relatively easy to make one dietary alteration but where two nutrients were involved it became more difficult.

Factors affecting compliance, recorded by Ornish et al. (1990), also include lack of motivation, inadequate dietary knowledge, poor education, low socio-economic status and difficulty in changing eating habits. Interestingly these factors can be moderated. So Fehily et al. (1991) found that social class had little influence on compliance but this may have been due to the high level of support provided. Hackett et al. (1990) found amongst children a difference in changing eating patterns which could be explained by social class but also notes that children from a higher social class had better eating habits initially. Reid et al. (1984) also note that poor eating habits and poor family support are factors which act to make change harder and often mean that the extent of the change needs to be greater. Fehily et al. (1991) suggest that percentage change should be the indicator rather than absolute values. Thomas (1979) notes that following the 'Look After Yourself' campaign even those who found change difficult still managed a small change.

Motivation can be judged by high rates of attendance and low rates of attrition (Seddon et al. 1981; Gallagher, 1984; Bush et al. 1988). But high motivation does not ensure success in all cases. Patients can still be poor compliers because they do not understand the advice. In a highly motivated group of patients suffering from multiple sclerosis a group of poor compliers was identified who considered themselves to be following the prescription rigorously (Fitzgerald et al. 1987) but were obviously failing to do so.

\section{FACTORS WHICH CAN INDICATE COMPLIANCE}

Body-weight is a unique indicator of compliance. It is of course the main indicator in obesity trials, although interpretation of what constitutes successful weight loss is debatable (Pearson, 1986). Individuals who are not overweight also seem to comply better with advice (Thomas, 1979). The men who poorly complied with advice following 
a coronary were overweight and at follow-up 6 years later had failed to lose and maintain any weight loss (Reid et al. 1984; Reid \& Mulcahy, 1987). In a study by McCulloch et al. (1983) the extent of dietary compliance was indicated by good metabolic control as monitored by glycosylated haemoglobin levels. Insulin-dependent women were seen to comply better than men and the underweight were more often found eating a 'traditional' pattern of meals. Both these markers were indicative of better metabolic control, although in this group only thirteen of seventy-five patients were thus classified. It has been noted elsewhere that women seem to do better than men in achieving a successful outcome (Thomas, 1979; Hackett et al. 1990). A separate slimming group for men achieved a better success rate than a mixed group (Pacy et al. 1987). Therefore, it may be prudent to examine the male:female ratio in any group when considering studies for their effectiveness.

Fehily et al. (1991) observe that dietary advice is frequently given but the degree to which advice is followed is rarely reported. This may be because it is difficult to monitor dietary change (Reid et al. 1984).

The very act of monitoring can affect choice and amount consumed (Bingham, 1987; Bull et al. 1991). The method of recording the information can also affect the precision of the information, and this in turn has an effect on interpreting whether a change has actually occurred or whether the change is due to experimental error. 'Because all forms of self-reported intake are subject to bias, collateral and physiological measures are frequently used in combination with self-reported data' (Wylie-Rosett et al. 1990). In some studies it may be possible to use non-invasive tools to assess whether change in dietary intake has occurred. Weight loss and skinfolds can give indication of body composition changes (Hunt-Pellow, 1986) following nutrition advice. The problem with these non-food measures is that they do not indicate whether dietary advice has been explicitly followed or some other strategy employed by the individual. When the outcome is in an unfavourable direction it is assumed the advice is not being followed and the diet may be re-inspected. But the opposite is not true; therefore, there is a dearth of information regarding determinants of compliance with the actual advice offered (Fehily et al. 1991) and especially when there is a successful outcome. Independent markers may be one way to follow compliance (Bingham, 1987; Warwick \& Williams, 1987). Hyman et al. (1982) have suggested that in many studies qualitative data may prove to be just as valid as quantitative data.

\section{IMPROVING COMPLIANCE AND EFFECTIVENESS}

Dietitians have traditionally taught on a one-to-one basis (Fieldhouse, 1979). Davidson et al. (1987) review how communication between therapist and patient can be improved. They suggest that all therapists need to consider how interviews can be conducted to take account of the cognitive limitations of their patients and how to involve them more in their own decision-making. de Weerdt et al. (1985) found that diabetic patients with a high locus of control benefited from an extended education programme designed to improve active self-care. Unfortunately, while certain aspects of their diabetic control improved, their diet did not. Davidson et al. (1987) also suggest that supportive follow-up of a socio-emotional nature should be arranged. Pacy et al. (1987) note that one of the successes of their slimming clubs is to enable individuals to re-register on further courses and, thus, get support for weight maintenance. However, dietitians will 
certainly need to consider carefully how patients may be encouraged to return (Seddon et al. 1981; Gallagher, 1984) and how this workload can be supported.

The use of group therapy, often with an emphasis on behaviour modification, in the treatment of obesity has proved successful in some studies (Jones et al. 1986) while in others it has not been so conclusive (Long et al. 1983; Adams et al. 1986). However, both Munvers (1953) and Long et al. (1983) make the point that the time saved in therapeutic time makes the group technique time efficient. It would be of interest to see more studies conducted on the use of this method for other diet therapies.

The use of printed material may also improve effectiveness of therapy. Jones et al. (1986) found the use of leaflets was most effective when combined with a group teaching session. The group sessions facilitated discussion and exchange of ideas on weight reduction. Leaflets used on their own have proved effective at informing and improving knowledge but have little effect on dietary change (Murray et al. 1984). A similar picture was seen for a nutrition education campaign in a large canteen. The leaflets and star-rating message on foods in the canteen were clearly of interest to $90 \%$ of the work-force but when asked if they had made any changes to their diet only $16 \%$ replied positively (Williams \& Poulter, 1991). In the clinic situation the use of simple dietary advice for diabetics proved to be just as effective in promoting control as the more complex information (Mitchell et al. 1990). Lambert et al. (1991) assessed compliance with advice regarding fibre consumption either given by a dietitian or an unqualified individual. Compliance was equally good. The use of literature can, therefore, be highly effective when used in appropriate ways (Jones et al. 1986).

The extent to which people can make changes must rely on their ability to rate their own diet for its nutritional content and then be able to select for change.

This is a difficult process and unfortunately the use of food labelling does not necessarily facilitate this process (Yeomans, 1986). An understanding of how people make their food choice could help dietitians to be more effective. Shepherd (1990) has written an excellent review of the factors which may influence individuals and their food choice. In a study to look at the selection of foods which provide fat in the diet (Shepherd \& Stockley, 1985) age and social class did not affect response but women reported a lower choice of foods containing fat and this was significantly related to their beliefs about fat. Beliefs involving the taste and flavour of foods are very important in determining which foods are chosen. Beliefs and attitudes towards the health benefits of certain foods are not so strongly correlated to choice (Shepherd, 1990). While the taste of food has a strong influence on what is chosen this does not appear to be the case for low-fat milk (Shepherd, 1988). Studying the beliefs and attitudes which people hold about food before giving dietary advice does not seem to be an explicit part of therapy offered by dietitians.

Finally, a few studies have specifically tried to assess the effectiveness of the dietitian. Hull et al. (1980) reported that $60 \%$ of the elderly residents in a long-term hospital improved their bowel habits when bran was added to their cereal. This effected a reduction in the use of laxatives and, hence, was cost effective. Le Cornu (1991) assessed the cost of maintaining hypercholesterolaemic patients on drug therapy compared with dietary intervention. A large reduction in cost was achieved and blood lipid levels were controlled. Lauder (1988) working in the UK also noted that feeding patients at home on enteral regimens improves quality of life and unblocks beds in a busy acute ward.

The calculations which are used to estimate effectiveness are open to debate. Thus, 
Orstead et al. (1985) claimed a more effective outcome to pregnancy with less low-birth-weight babies being born following a counselling programme which commenced prenatally. Disbrow (1985) challenged the calculations and the claim. This dialogue and discussion was the result of therapists looking in detail at the results of their therapy. Perhaps one of the major benefits to the therapists of asking the question "is diet therapy effective?' is to stimulate inspection and debate. This can only serve to improve our understanding about many factors which affect people, their nutrition and health. Dietitians are uniquely placed to do this and the foregoing, largely based on the reported studies by dietitians, is helping to achieve an answer to the question 'is our dietary advice effective?'.

\section{REFERENCES}

Adams, S. O., Grady, K. E. \& Mukaida, C. (1986). A comparison of group and individual interventions, Journal of American Dietetic Association 86, 485-490.

Bingham. S. (1987). Dietary intake. Nutrition Abstracts \& Reviews 57, no. 10.

Bloom, A. (1967). Relationship of the complications of diabetes to the clinical state. Proceedings of the Royal Society of Medicine 60, 149.

Bradley, A. \& Theobald, A. (1988). The effects of dietary modification as defined by NACNE on the eating habits of 28 people. Journal of Human Nutrition \& Dietetics 1, 105-114.

Bull, N. L., Wheeler, E. F. \& Gatenby, S. J. (1991). A combination method of dietary survey: report of a field trial. Journal of Human Nutrition \& Dietetics 4, 207-218.

Bush, A., Webster, J., Chalmers, G., Pearson, M., Penfold, P., Brereton, P. \& Garrow, J. S. (1988). The Harrow Slimming Club: report on 1090 enrolments in 50 courses 1977-86. Journal of Human Nutrition \& Dietetics 1, 429-436.

Cole-Hamilton, I., Gunner, K., Leverkus, C. \& Stanway, J. (1986). A study among dietitians and adult members of their households of the practicalities and implications of following proposed dietary guidelines for the UK. Human Nutrition: Applied Nutrition 40A, 365-389.

Davidson, C., Kowalska, A. Z., Nutman, P. N. S. \& Pearson, G. C. (1987). Dietitian-patient communication: a critical appraisal and approach to training. Human Nutrition: Applied Nutrition 41A, 381-389.

Department of Health (1991). The Health of the Nation: A Consultative Document for Health in England. London: H.M. Stationery Office.

de Weerdt, I., Visser, A. P.. Kok, G. \& van der Veen, E. A. (1985). Randomized controlled evaluation of an education program for insulin treated patients with DM: effects on psychosocial variables. Patient Education \& Counselling 14, 191-215.

Disbrow, D. (1985). Cost effectiveness of nutrition counselling. Journal of American Dietetic Association 85, 1228-1232.

Drexler, L. \& Caliendo, M. A. (1980). Developing and implementing a nutritional care audit. Thresholds of performance levels acceptable for audit eg 85\%. Journal of American Dietetic Association 76, 374-377.

Fehily, A. M., Vaughan-Williams, E., Shiels, K., Williams, A. H., Horner, M., Bingham, G., Holliday, R. M., Sweetman, P. M. \& Burr, M. L. (1991). Factors influencing compliance with dietary advice: the Diet and Reinfarction Trial (DART). Journal of Human Nutrition \& Dietetics 4, 33-42.

Fieldhouse, P. (1979). An interview model for use in dietetic training. Journal of Human Nutrition 33, 206-210.

Fitzgerald, G., Harbige, L. S., Forti, A. \& Crawford, M. A. (1987). The effect of nutritional counselling on diet and plasma EFA status in multiple sclerosis patients over 3 years. Human Nutrition: Applied Nutrition 41 A, 297-310.

Gallagher, C. (1984). Next please: a review of dietetic outpatient attendance. Human Nutrition: Applied Nutrition 38A, 181-186.

Hackett, A. F. Jarvis, S. N. \& Matthews, J. N. S. (1990). A study of the eating habits of 11-12 yr old children before and one year after the start of a healthy eating campaign in Northumberland. Journal of Human Nutrition \& Dietetics 3, 323-332.

Hull, C., Greco, R. S. \& Brooks, D. L. (1980). Alleviation of constipation in the elderly by dietary fibre supplementation. Journal of American Geriatric Society 28, 410-417. 
Hunt-Pellow, J. (1986). Skinfold assessment as an intervention technique: One aspect of a nutrition education program. Journal of American Dietetic Association 86, 369-374.

Hyman, M. D., Insull, W., Palmer, R. H., O’Brian, J., Gordon, L. \& Levine, B. (1982). Assessing methods for measuring compliance with a fat controlled diet. American Journal of Public Health 72, 152-160.

Jones, S. E., Owens, H. M. \& Bennett, G. A. (1986). Does behaviour therapy work for dietitians? An experimental evaluation of the effects of three procedures in a weight reduction clinic. Human Nutrition: Applied Nutrition 40A, 272-281.

Lambert, J. P., Morrison, V., Brunt, P. W., Mowat, N. A. G., Eastwood, M. A. \& Dickerson, J. W. T. (1991). Dietary fibre intake of irritable bowel patients prescribed a high fibre diet. Journal of Human Nutrition \& Dietetics 4, 155-164.

Lauder, N. (1988). Enteral nutrition - home or hospital? Journal of Human Nutrition \& Dietetics 1, 372.

Le Cornu, K. (1991). Audit of dietary input into a hospital lipid clinic. Journal of Human Nutrition \& Dietetics 4, 121-126.

Ley, P. (1982). Satisfaction, compliance and communication. British Journal of Clinical Psychology 21, 241-254.

Long, C. G., Simpson, C. M. \& Allott, E. A. (1983). Psychological and dietetic counselling combined in the treatment of obesity: a comparative study in a hospital outpatient clinic. Human Nutrition: Applied Nutrition 37A, 94-102.

McCulloch, D. K., Young, R. J., Steel, J. M., Wilson, E. M., Prescott, R. J. \& Duncan, L. J. P. (1983). Effect of dietary compliance on metabolic control in insulin-dependent diabetics. Human Nutrition: Applied Nutrition 37A, 287-292.

MacDonald, A. (1990). Measuring clinical outcome. Journal of Human Nutrition \& Dietetics 3, 71-78.

MacDonald, A. \& Forsythe, W. I. (1986). The cost of nutrition and diet therapy for low-income families. Human Nutrition: Applied Nutrition 40A, 87-96.

McManners, M. H. \& Barina, S. A. (1984). Productivity in clinical dietetics. Journal of American Dietetic Association 84, 1035-1041.

Mitchell, R. D., Nowakowska, J. A. \& Hurst, A. J. (1990). Comparison of official 10 g carbohydrate exchange system with simplified dietary advice in insulin dependent diabetics. Journal of Human Nutrition \& Dietetics 3, 19-26.

Munvers, E. D. (1953). Dietetic interview or group discussion - decision in reducing. Journal of American Dietetic Association 29, 1197-1199.

Murray, M., Rona, R. J., Morris, R. W. \& Tait, N. (1984). The smoking and dietary behaviour of Lambeth school children. I. The effectiveness of an anti-smoking and nutrition education programme for children. Public Health 98, 163-224.

Nichols, S., Waters, W. E., Woolaway, M. \& Hamilton-Smith, M. B. (1988). Evaluation of the effectiveness of a nutritional health education leaflet in changing public knowledge and attitudes about eating and health. Journal of American Dietetic Association 1, 233-238.

Ornish, D. M., Brown, S. E., Scherwitz, L. W., Billings, J. H., Armstrong, W. T., Ports, T. A., McLanahan, S. M., Kirkeeide, R. L., Brand, R. J. \& Gould, K. L. (1990). Can lifestyle change reverse coronary heart disease? Lancet 1, 129-133.

Orstead, C., Arrington, D., Kamath, S. K., Olson, R. \& Kohns, M. B. (1985). Efficacy of prenatal nutrition counselling: Weight gain, infant birth weight and cost-effectiveness. Journal of American Dietetic Association 85, 40-48.

Pacy, P. J., Webster, J. D., Pearson, M. \& Garrow, J. S. (1987). A cross-sectional cost/benefit audit in a hospital obesity clinic. Human Nutrition: Applied Nutrition 41A, 38-46.

Pearson, G. C. (1986). The dietetic treatment of obesity in community and hospital clinics. MPhil Thesis (CNAA), Leeds Polytechnic.

Reid, V., Graham, I., Hickey, N. \& Mulcahy, R. (1984). Factors affecting dietary compliance in coronary patients included in a secondary prevention programme. Human Nutrition: Applied Nutrition 38A, 279-287.

Reid, V. \& Mulcahy, R. (1987). Nutrient intakes and dietary compliance in cardiac patients: 6 yr follow-up. Human Nutrition: Applied Nutrition 41A, 311-318.

Seddon, R., Penfound, J. \& Garrow, J. S. (1981). The Harrow Slimming Club: analysis of the results obtained in 249 members of a self-financing, non-profit making group. Journal of Human Nutrition 35, $128-135$.

Shepherd, R. (1988). Belief structure in relation to low-fat milk consumption. Journal of Human Nutrition \& Dietetics 1, 421-428. 
Shepherd, R. (1990). Overview of factors influencing food choice. British Nutrition Foundation Bulletin 15, Suppl. 1, 12-30.

Shepherd, R. \& Stockley, L. (1985). Fat consumption and attitudes towards food with a high fat content. Human Nutrition: Applied Nutrition 39A, 431-442.

Simko, M. D. \& Conklin, M. T. (1989). Focusing on the effectiveness side of the cost-effectiveness equation. Journal of American Diet Association 89, 485-487.

Thomas, J. (1979). Look after yourself, monitoring the effects of a campaign. Journal of Human Nutrition 33, 376-382.

Warwick, P. M. \& Williams, L. T. (1987). Dietary intake of individuals interested in eating a healthy diet: a validated study of intake before and after advice. Human Nutrition: Applied Nutrition 41A, 409-425.

Williams, C. \& Poulter, J. (1991). Formative evaluation of a workplace menu labelling scheme. Journal of Human Nutrition \& Dietetics 4, 251-262.

Wylie-Rosett, J., Wassentheil-Smoller, S. \& Elmer, P. (1990). Assessing dietary intake for patient education planning and evaluation. Patient Education \& Counselling 15, 215-227.

Yeomans, L. (1986). The practical use of nutrition labels. British Nutrition Foundation Bulletin 11, 12-22.

Yudkin, J. (1958). This Slimming Business. London: MacGibbon \& Kee. 